the sleep, ${ }^{7}$ though sometimes the attack passes on to paradoxical sleep with later description of dreaming and paralysis. ${ }^{8}$ The incidence of sleep paralysis and of cataplexy can be controlled by those tricyclic antidepressant drugs that suppress paradoxical sleep, particularly chlorimipramine and imipramine. Dosage of $50-100 \mathrm{mg}$ daily should be adjusted to the individual. Unfortunately these drugs do not prevent the sleep attacks of narcoleptics and should not be used concurrently with amphetamine.

Most ordinary nightmare dreams occur during the usual dream-sleep periods, that is in paradoxical sleep with its associated paralysis. A few, however, occur as sudden events in the other kind of natural sleep, namely, orthodox sleep (which occupies about $75 \%$ of the night) and do so when it is in its deepest stage. From this same stage sleepwalking also has its origins. A study of these nightmares has lately been reported by C. Fisher and colleagues, ${ }^{9}$ who found it possible sometimes to provoke them by abruptly rousing the patient. Whether spontaneous or provoked they were characterized by brief, overwhelming terror, very little phantasy content, and often by major bodily movements or sleep-walking, with mental confusion and subsequent amnesia. When these night-terrors occur in childhood the disorientated child usually recalls nothing of them in the morning, a fact which may console the alarmed parents.

Experiments on cerebral electrical responsiveness suggest that this kind of nightmare (sometimes called an incubus) may be really a disorder of the arousal mechanism. ${ }^{10}$ Brain anxiety- and alertness-mechanisms usually parallel one another, and drugs that diminish anxiety also reduces alertness. It seems as if separate brain mechanisms for anxiety-arousal and wakefulness-arousal may be suddenly activated together yet get badly out of step and cause the night-terror. A period of treatment with diazepam, which prevents the deepest orthodox sleep and also reduces anxiety, has been found to alleviate these night-terrors in those rare adults for whom they are recurrent events. ${ }^{11}$ \footnotetext{
Mack, J. E., Nightmares and Human Conflict. Little, Brown and Company,
Boston, 1970.

2 Jouvet, M., Archives Italiennes de Biologie, 1962, $100,125$.

8 Oswald, I., Lancet, 1962, $2,935$. - Oswald, I., Lancet, 1962, 2, 935.
Freniatria, 1969, 93, 950.

5 Evans, J. I., and Oswald, I., British Fournal of Psychiatry, 1966, 112, 401 .

- Hishikawa, Y., and Kaneko, Z., Electroencephalography and Clinical Neurophysiology, 1965, 18, 249.

7 Rechtschaffen, A., and Dement, W., Research Publications, Association 7 Rechtschaffen, A., and Dement, W., Research Publications,

for Research in Nervous and Mental Disease, 1967, 45,
8 Scollo-Lavizzari, G., European Neurology, 1970, 4, 57.

- Fisher, C., Byrne, J., Edwards, A., and Kahn, E., Fournal of the American Psychoanalytic Association, 1970, 18, 747.

10 Broughton, R. J., Science, 1968, 159, 1070.

11 Fisher, C., Kahn, E., Edwards, A., and Davis, D., Psychophysiology, 1971,8 , in press.
}

\section{Thorns in the Bone}

Four to sixteen weeks or so after a penetrating wound from a thorn the injured person may develop a painful swelling at the site of the trauma. The tumour is not warm or red, there is no lymphadenopathy or leucocytosis, and the patient is afebrile. Because of the length of the quiescent period before the secondary manifestations develop the causative accident may have been forgotten. $X$-ray examination shows a lesion in the underlying bone in the form of an osteolytic or a periosteal reaction. ${ }^{1}$
These pseudotumours of bone after penetration by a thorn occur mainly in children and mostly in a hand or foot, though two cases of lesions in the fibula have been recorded. ${ }^{1}$ Only eight cases in all have been reported, but that might not be the true incidence since medical advice may not have been sought for the primary injury or the cause recognized then or later. Thorns are radiolucent, and until bony changes occur $x$-ray examination is negative.

It is not known why the changes in the bone occur. It is reasonable to suspect an inflammatory reaction to infection to be the cause, but on only one occasion has there been a positive bacteriological culture to support the theory. The histology is merely that of a non-specific granulomatous reaction. Most organic foreign materials when embedded in or near bone do not evoke enough response in the neighbouring osseous structures to be recognized radiologically. ${ }^{2}$ Then why this reaction to thorns-not just one type of thorn but several? Perhaps a thorn releases a toxin which is the causative agent. This hypothesis has yet to be proved.

All but two of the thorn-induced pseudotumours reported by $R$. D. Gerle ${ }^{1}$ showed both osteolytic and periosteal reaction. The osteolytic changes were cystic, with clear, often sclerosed margins and a benign appearance. The periosteal reactions, on the other hand, were difficult to differentiate from malignant tumours. One, in the fibula, was indistinguishable from a Ewing's sarcoma. Biopsy revealed the true nature of the lesion. Osteosarcoma and osteoid osteoma are also mimicked. A child presenting with a swollen, painful lesion on a hand or foot which does not show the classical signs of acute inflammation must arouse suspicion of the presence of a thorn. Once the diagnosis is made cure is easily achieved by surgical exploration, removal of the thorn, and primary closure of the wound. Within a few months the bone is radiologically normal.

1 Gerle, R. D., British fournal of Radiology, 1971, 44, 642.

2 Bunnel, S., Surgery of the Hand, 3rd edn., Philadelphia, Lippincott, 1956.

\section{Taste and Smell}

Taste and smell usually go together. Gastronomic delights and the enjoyment of nature are taken for granted until a common cold interferes with normal smell. Patients with temporal lobe seizures may complain of a distortion of the senses of smell or taste during the attacks or as part of the epileptic aura. This interruption of a normal sensory function is short-lived, but in cases of head injury with fractures through the anterior fossa on either side of the ethmoid bone there may be more permanent loss of smell and consequent disturbance in taste appreciation.

The senses of smell and taste may also be disturbed without any history of trauma to the head, and a new syndrome has been proposed under the title of "idiopathic hypogeusia, hyposmia, and dysosmia".1 The authors of the report, R. I. Henkin and colleagues, of the National Institutes of Health, Bethesda, have collected 35 cases of disordered taste sensibility, including a decrease in acuity and obnoxious, perverted appreciation of food and drink. The distortion in taste included persistent saltiness, sweetness, sourness, bitterness, and metallic tastes. It occurred without food and could not be relieved. Other symptoms, not always present, included a persistent foul smell, vertigo, impairment of hearing, loss of 